\title{
Robot-assisted pancreaticoduodenectomy: safety and feasibility
}

This article was published in the following Dove Press journal:

Robotic Surgery: Research and Reviews

4 June 2015

Number of times this article has been viewed

\section{Emanuele Federico \\ Kauffmann' \\ Niccolò Napoli ${ }^{\prime}$ \\ Mario A Belluomini' \\ Mario Miccoli ${ }^{2}$ \\ Stefania Brozzetti ${ }^{3}$ \\ Ugo Boggi'}

'Division of General and Transplant Surgery, ${ }^{2}$ Biostatistics Unit Research,

Department of Clinical and Experimental Medicine, University of Pisa, Pisa, Italy; ${ }^{3}$ Pietro Valdoni Department of Surgery, University of Rome La Sapienza, Rome, Italy
Correspondence: Emanuele Federico Kauffmann

Azienda Ospedaliera Universitaria Pisana, Università di Pisa, Via Paradisa 2, 56|24,

Pisa, Italy

Tel +39050996926

Fax +39050996800

Email ekauffmann@hotmail.it
Background: The availability of robotic assistance could make laparoscopic pancreaticoduodenectomy safely feasible. We herein provide a systematic review on laparoscopic robot-assisted pancreaticoduodenectomy (RAPD).

Methods: Literature search was conducted on multiple databases considering articles published in English up to October 31, 2014, reporting on ten or more patients.

Results: A total of 262 articles were identified. Excluding duplicates $(n=172)$, studies not matching inclusion criteria $(n=77)$, and studies not suitable for other reasons $(n=6)$, a total of seven studies reporting on 312 RAPDs were eventually reviewed. These studies were either retrospective cohort studies $(n=4)$ or case-matched studies $(n=3)$. No randomized controlled trial was identified. Most patients undergoing RAPD were diagnosed with malignant tumors $(224 / 312 ; 71.8 \%)$. RAPD was feasible in most patients. Conversion to open surgery was reported in $9.2 \%$ of the patients. A hybrid RAPD technique, employing standard laparoscopy or open surgery through a mini-incision, was adopted in most patients $(178 / 312 ; 57.0 \%)$. Overall, there were six postoperative deaths at 30 days $(6 / 312 ; 1.9 \%)$, including one intraoperative death caused by portal vein injury, while 137 out of 260 patients with complete information developed postoperative complications (52.7\%). The mean length of hospital stay ranged from 10-29 days. Postoperative pancreatic fistula (POPF) occurred in 66 patients $(66 / 312 ; 21.1 \%)$. Grade C POPF was reported in eight patients $(8 / 312 ; 2.5 \%)$. The costs of RAPD were assessed in two studies, demonstrating additional costs ranging from 4,000-5,000 US dollars to 6,193 Euro. The mean number of examined lymph nodes and the rate of positive surgical margins indicate that RAPD could be an appropriate oncologic operation.

Conclusion: RAPD is safely feasible. These results were obtained in selected patients and in specialized centers. RAPD should not be implemented in the occasional patient by surgeons without advanced laparoscopic skills and formal training in robotic surgery.

Keywords: robotic surgery, da Vinci, pancreaticoduodenectomy, pancreatectomy, laparoscopy

\section{Introduction}

First described in 1994 by Gagner and Pomp, ${ }^{1}$ laparoscopic pancreaticoduodenectomy (PD) is eventually gaining momentum in specialized centers. ${ }^{2}$ The intrinsic limitations of conventional laparoscopy, the lack of standardized training in advanced laparoscopy for the earlier generations of pancreatic surgeons, and the technical challenges of PD are among the major factors that have limited the acceptance of laparoscopic PD. The enhanced dexterity offered by the da Vinci surgical system (dVss) (Intuitive Surgical, Sunnyvale, California, USA) offers the unique opportunity to verify if the well-known advantages of laparoscopy can be experienced also by patients undergoing PD. ${ }^{3}$ 
Further, the use of the dVss could allow a greater proportion of pancreatic surgeons to safely pursue minimally invasive $\mathrm{PD}$, since robotic surgery is more intuitive than conventional laparoscopy. ${ }^{4}$

We herein provide a systematic review on robot-assisted PD (RAPD).

\section{Methods}

\section{Definition of RAPD}

For the purpose of this review, all procedures in which the dVss was used to perform a PD were defined as RAPD. This definition includes patients in whom the operation was carried out entirely under robotic assistance and patients in whom robotic assistance was limited to specific steps of the operation. The latter instance actually represents a hybrid procedure in which the use of robotic assistance is mixed with traditional laparoscopy and/or with traditional surgery carried out through a mini-laparotomy incision. There are several prototypes of "hybrid RAPD":

1. Laparoscopy is used for dissection and robotic assistance for digestive reconstruction. ${ }^{5}$

2. Laparoscopy is used for preliminary dissection and robotic assistance for dissection of the posterior margin/ uncinate process and for digestive reconstructions. ${ }^{6}$

3. Following robotic dissection, digestive reconstruction is entirely or partially carried out through a mini-laparotomy incision. $^{7}$

\section{Search methodology}

The literature search focused solely on articles published, between January 1, 2000 and October 31, 2014, in peerreviewed journals and in English. Studies were identified by searching multiple literature databases, including Scopus, Web of Science, and PubMed using the following keywords: "pancreaticoduodenectomy and robot*," "pancreatoduodenectomy and robot*," and "duodenopancreatectomy and robot*." Queries were limited to clinical studies. Hand searches of reference lists of relevant literature reviews were also performed.

\section{Selection of studies}

Randomized controlled trials, case-matched studies, and retrospective cohorts studies were all accepted, if reporting on ten or more RAPD.

\section{Data extraction and management}

Data were collected on customized tables. Each article was read and analyzed by at least two authors. In case of multiple

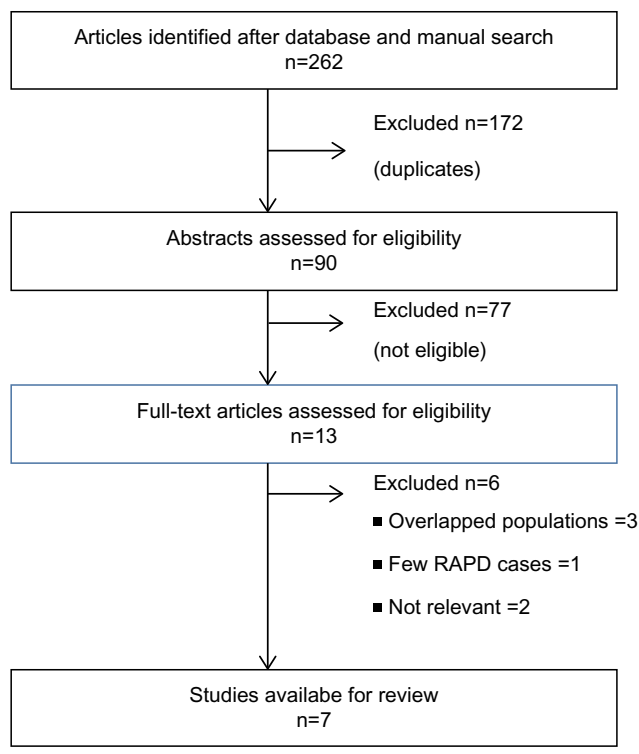

Figure I Flowchart of systematic review.

Abbreviation: RAPD, robot-assisted pancreaticoduodenectomy.

articles from the same working group, only the most recent or the more informative publication was considered in order to avoid duplication of the data.

\section{Results}

Initial queries identified a total of 262 articles from all databases and search methods. Comparison of the retrieved titles identified 172 studies that were duplicates, thus leaving 90 abstracts for further evaluation. Additional 77 studies did not meet the inclusion criteria, and six were excluded because of various reasons (Figure 1), eventually leaving seven studies for the review. These studies were either retrospective cohort studies $(n=4)^{6-9}$ or case-matched studies $(n=3),{ }^{5,10,11}$ all published between 2010 and 2013. No randomized controlled trial was identified.

Overall, the seven studies reported data on 312 RAPDs (Table 1).

Table I Reviewed series

\begin{tabular}{|c|c|c|c|c|}
\hline Study & Year & Country & Patients & Technique \\
\hline Giulianotti et al ${ }^{8}$ & 2010 & Italy/USA & 36 & RAPD \\
\hline Buchs et $\mathrm{al}^{10}$ & 2011 & USA & 44 & RAPD \\
\hline Chalikonda et $\mathrm{al}^{5}$ & 2012 & USA & 30 & Hybrid RAPD \\
\hline Lai et al" & 2012 & $\begin{array}{l}\text { People's Republic } \\
\text { of China }\end{array}$ & 20 & RAPD \\
\hline Zhan et $\mathrm{al}^{7}$ & 2013 & $\begin{array}{l}\text { People's Republic } \\
\text { of China }\end{array}$ & 16 & Hybrid RAPD \\
\hline Boggi et $\mathrm{al}^{9}$ & 2013 & Italy & 34 & RAPD \\
\hline Zureikat et al ${ }^{6}$ & 2013 & USA & 132 & Hybrid RAPD \\
\hline
\end{tabular}

Abbreviation: RAPD, robot-assisted pancreaticoduodenectomy. 
Table 2 Safety of RAPD

\begin{tabular}{|c|c|c|c|c|c|}
\hline Study & $\begin{array}{l}\text { Morbidity, } \\
\text { n (\%) }\end{array}$ & $\begin{array}{l}\text { POPF, } \\
\text { n (\%) }\end{array}$ & $\begin{array}{l}\text { Grade C POPF, } \\
\text { n (\%) }\end{array}$ & $\begin{array}{l}\text { 30-d mortality, } \\
\text { n (\%) }\end{array}$ & $\begin{array}{l}\text { Mean LOS, } \\
\text { d (SD) }\end{array}$ \\
\hline Giulianotti et $\mathrm{al}^{8}$ & NA & $13(36.1)$ & NA & I (2.7) & 28.7 (NA) \\
\hline Buchs et $\mathrm{al}^{10}$ & $16(36.4)$ & $8(18.1)$ & I (2.3) & $2(4.5)$ & $13(7.5)$ \\
\hline Chalikonda et $\mathrm{al}^{5}$ & $9(30)$ & $2(6.6)$ & I (3.3) & I (4) & 9.79 (NA) \\
\hline Lai et al"I & $10(50)$ & 7 (35) & NA & 0 & I3.7 (6.1) \\
\hline Zhan et $\mathrm{al}^{7}$ & $6(38)$ & I (6.3) & $0(0)$ & 0 & $23(7)$ \\
\hline Boggi et al ${ }^{9}$ & $19(55.8)$ & $13(38.2)$ & $0(0)$ & 0 & 23 (NA) \\
\hline Zureikat et $\mathrm{al}^{6}$ & $83(62.8)$ & $22(17)$ & $5(3.7)$ & $2(1.5)$ & 10 (NA) \\
\hline
\end{tabular}

Abbreviations: RAPD, robot-assisted pancreaticoduodenectomy; POPF, postoperative pancreatic fistula; LOS, length of hospital stay; d, day; NA, not available.

\section{Current status}

Our review shows that just a few hundreds of RAPDs have been reported worldwide. The fact that all RAPDs were reported in recent years, if on one hand, testifies a growing interest around this new technique, on the other, demonstrates that this operation is still being performed only by pioneers and is yet under development. Perhaps because of this, there is no agreement on patient selection criteria. Looking at the demographics of the reported series, it seems that older patients are avoided (mean patient age ranging from 60.0 to 66.4 years) and that lean patients are preferred (mean body mass index ranging from 24.2 to $27.7 \mathrm{~kg} / \mathrm{m}^{2}$ ). As expected, most patients undergoing PD were diagnosed with malignant tumors $(224 / 312 ; 71.8 \%)$. Prevalence of malignant tumors among reviewed series ranged from $46.0 \%$ and $83.3 \%$.

The variability of the techniques used, despite all authors employing robotic assistance at least at some stages during PD, shows also that most technical details of RAPD have to be defined yet. The hybrid approach was used in most patients $(178 / 312 ; 57.0 \%)$, but most authors used a fully robotic technique $(4 / 7 ; 57.1 \%)$.

\section{Safety}

Overall, there were six postoperative deaths at 30 days (6/312; $1.9 \%$ ), while 137 out of 260 patients with complete information developed postoperative complications (52.7\%). Postoperative pancreatic fistula (POPF) occurred in 66 patients $(66 / 312 ; 21.1 \%)$. Grade C POPF was reported in eight patients $(8 / 312 ; 2.5 \%)$ (Table 2$)$.

It is worth noting that one intraoperative death occurred following injury to the portal vein, despite prompt conversion to open surgery. ${ }^{5}$

In retrospective cohort studies, postoperative mortality ( $\leq 30$ days) ranged from $0 \%$ to $2.7 \%$ (mean $1.0 \%$ ), while overall morbidity ranged from $38.0 \%$ to $62.8 \%$ (mean $52.2 \%$ ). Incidence of POPF ranged from $6.3 \%$ to $38.2 \%$ (mean 24.4\%). Grade C POPF occurred in five out of 182 patients with complete information (2.7\%).

In case-matched studies, postoperative mortality ( $\leq 30$ days) ranged from $0 \%$ to $4.5 \%$ (mean $2.8 \%$ ), while overall morbidity ranged from $30.0 \%$ to $50.0 \%$ (mean $38.8 \%$ ). Incidence of POPF ranged from $6.7 \%$ to $35.0 \%$ (mean 19.9\%). Grade C POPF occurred in three out of 94 patients with complete information (3.1\%).

Figures on POPF should be read considering that most pancreases $(91.2 \%)$ were reported as being soft.

The mean length of hospital stay ranged from 10 to 29 days, possibly reflecting the differences in postoperative management and policies on patient discharge from the hospitals.

The need for re-operation ( $\leq 90$ postoperative days) ranged from $3.0 \%$ to $10.0 \%$.

\section{Feasibility}

RAPD was feasible in the vast majority of selected patients. Conversion to open surgery occurred between $0 \%$ and $25.0 \%$ of the patients.

In retrospective cohort studies, the mean operative time ranged from 400.5 to 597.0 minutes with an estimated mean intraoperative blood loss ranging from $220.0 \mathrm{~mL}$ to $633.8 \mathrm{~mL}$.

Table 3 Feasibility of RAPD

\begin{tabular}{llll}
\hline Study & Conversion & $\begin{array}{l}\text { Mean operative } \\
\text { time }\end{array}$ & $\begin{array}{l}\text { Mean blood } \\
\text { loss }\end{array}$ \\
\hline Giulianotti et al $^{8}$ & $\mathrm{NA}$ & 400.5 minutes & $250.0 \mathrm{~mL}$ \\
${\text { Buchs et } \mathrm{al}^{10}}$ & $2(4.5 \%)$ & 444.0 minutes & $387.0 \mathrm{~mL}$ \\
${\text { Chalikonda et } \mathrm{al}^{5}}$ & $3(10 \%)$ & 476.0 minutes & $485.0 \mathrm{~mL}$ \\
${\text { Lai et } \mathrm{al}^{\prime \prime}}^{\text {Zhan et } \mathrm{al}^{7}}$ & $\mathrm{I}(5 \%)$ & 491.5 minutes & $247.0 \mathrm{~mL}$ \\
${\text { Boggi et } \mathrm{al}^{9}}_{\text {Zureikat et al }^{6}}$ & 0 & 479.7 minutes & $633.8 \mathrm{~mL}$ \\
\hline
\end{tabular}

Abbreviations: RAPD, robot-assisted pancreaticoduodenectomy; NA, not available. 
Table 4 Technical details of RAPD

\begin{tabular}{|c|c|c|c|c|c|c|c|c|}
\hline Study & Ports & Optic port & $\begin{array}{l}\text { Fourth } \\
\text { robotic arm }\end{array}$ & Energy device & $\begin{array}{l}\text { Closure } \\
\text { of GDA }\end{array}$ & $\begin{array}{l}\text { Section of the } \\
\text { pancreatic neck }\end{array}$ & Extraction site & Drains \\
\hline Giulianotti et $\mathrm{al}^{8}$ & 5 & Pararectal & Right & Harmonic scalpel & Ligature & Harmonic scalpel & Pfannenstiel & Yes \\
\hline Buchs et $\mathrm{al}^{10}$ & - & - & - & - & - & - & Pfannenstiel & Yes \\
\hline Chalikonda et a $\left.\right|^{5}$ & 6 & Umbilical & No & Harmonic scalpel & Clips & Ultrasonic shear & Enlarged port site & Yes \\
\hline Lai et al" & 5 & Sub-umbilical & Left & Ligasure & Clips & - & Pfannenstiel & Yes \\
\hline Zhan et $\mathrm{al}^{7}$ & 5 & Umbilical & Right & Harmonic scalpel & - & - & Enlarged port site & Yes \\
\hline Boggi et al ${ }^{9}$ & 5 & Pararectal & Left & Harmonic scalpel & Ligature & Scissors & Pfannenstiel & Yes \\
\hline Zureikat et $\mathrm{al}^{6}$ & 8 & Para-umbilical & Right & Ligasure & Ligature & Cautery hook & Enlarged port site & Yes \\
\hline
\end{tabular}

Abbreviations: RAPD, robot-assisted pancreaticoduodenectomy; GDA, gastroduodenal artery.

Table 5 Main histopathology parameters

\begin{tabular}{|c|c|c|c|c|c|}
\hline & \multicolumn{3}{|l|}{ Tumor type } & \multirow{2}{*}{$\begin{array}{l}\text { Lymph } \\
\text { nodes, } \\
\text { n (\%) }\end{array}$} & \multirow{2}{*}{$\begin{array}{l}\text { R0, } \\
\text { n (\%) }\end{array}$} \\
\hline & $\begin{array}{l}\text { Malignant, } \\
\text { n (\%) }\end{array}$ & PDAC & $\begin{array}{l}\text { Benign, } \\
\text { n (\%) }\end{array}$ & & \\
\hline Giulianotti et $\mathrm{al}^{8}$ & $24(67.7 \%)$ & 13 & $12(33.3 \%)$ & 21 (NA) & $24(100 \%)$ \\
\hline Buchs et $\mathrm{al}^{10}$ & 33 (75\%) & 22 & II (25\%) & $16.8(10)$ & 30 (90.9\%) \\
\hline Chalikonda et al ${ }^{5}$ & 14 (46\%) & 14 & $16(54.5 \%)$ & I 3.2 (NA) & 14 (100\%) \\
\hline Lai et al"I & I5 (75\%) & 7 & $5(25 \%)$ & $9.87(6)$ & II (73.3\%) \\
\hline Zhan et $\mathrm{al}^{7}$ & $10(62.5 \%)$ & 7 & $6(37.5 \%)$ & NA & $10(100 \%)$ \\
\hline Boggi et $\mathrm{al}^{9}$ & $22(64.7 \%)$ & 5 & $12(35.3 \%)$ & 32 (NA) & $22(100 \%)$ \\
\hline Zureikat et $\mathrm{al}^{6}$ & 106 (80.3\%) & 54 & $26(19.7 \%)$ & 19 (NA) & 93 (87.7\%) \\
\hline
\end{tabular}

Abbreviations: PDAC, pancreatic ductal adenocarcinoma; NA, not available; R0, margin negative resection.

\section{Mean length of hospital stay}

\begin{tabular}{|c|c|c|c|c|c|c|c|}
\hline \multirow[t]{2}{*}{$\underline{\text { Study name }}$} & \multicolumn{7}{|c|}{ Statistics for each study } \\
\hline & $\begin{array}{l}\text { Difference } \\
\text { in means }\end{array}$ & $\begin{array}{c}\text { Standard } \\
\text { error }\end{array}$ & Variance & $\begin{array}{l}\text { Lower } \\
\text { limit }\end{array}$ & $\begin{array}{c}\text { Upper } \\
\text { limit }\end{array}$ & $Z$-value & $P$-value \\
\hline Buchs et al ${ }^{10}$ & 1.600 & 1.891 & 3.576 & -2.106 & 5.306 & 0.846 & 0.398 \\
\hline Chalikonda et al ${ }^{5}$ & 3.470 & 1.677 & 2.812 & 0.183 & 6.757 & 2.069 & 0.039 \\
\hline Lai et al'11 & 12.100 & 3.794 & 14.398 & 4.663 & 19.537 & 3.189 & 0.001 \\
\hline & 4.600 & 2.291 & 5.249 & 0.109 & 9.090 & 2.008 & 0.045 \\
\hline
\end{tabular}

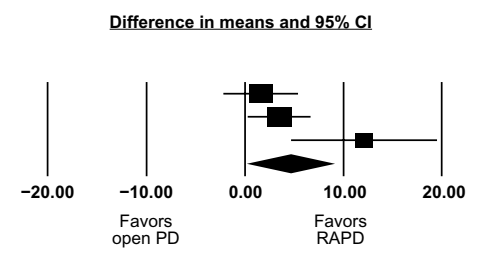

Figure 2 Meta-analysis of mean length of hospital stay.

Abbreviations: RAPD, robot-assisted pancreaticoduodenectomy; PD, pancreaticoduodenectomy; Cl, confidence interval.

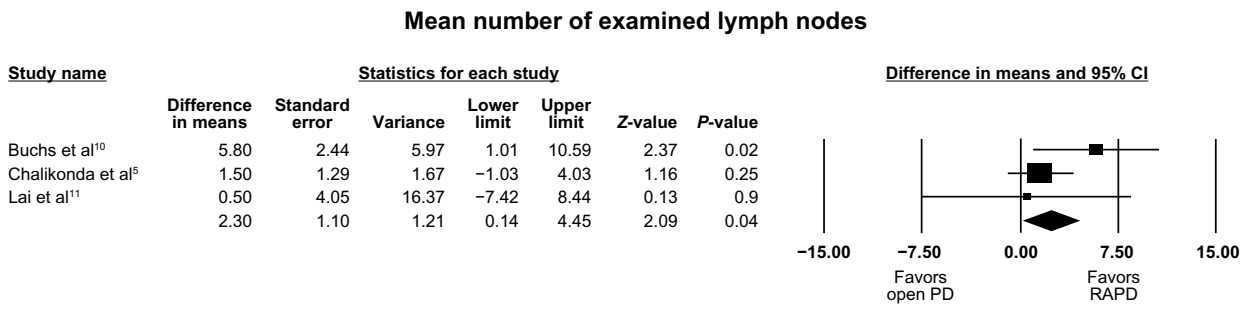

Figure 3 Meta-analysis of mean number of examined lymph nodes.

Abbreviations: RAPD, robot-assisted pancreaticoduodenectomy; PD, pancreaticoduodenectomy; $\mathrm{Cl}$, confidence interval.

Table 6 Meta-analysis of RAPD vs open PD (P-values)

\begin{tabular}{lllllllll}
\hline Study & $\begin{array}{l}\text { Operative } \\
\text { time }\end{array}$ & LOS & Ro & $\begin{array}{l}\text { Lymph } \\
\text { nodes }\end{array}$ & $\begin{array}{l}\text { Malignant } \\
\text { tumors }\end{array}$ & Morbidity & POPF & Mortality \\
\hline Buchs et al $^{10}$ & $0.00 I^{*}$ & 0.398 & 0.362 & $0.018^{*}$ & 0.558 & 0.257 & 0.788 & 0.634 \\
Chalikonda et al $^{5}$ & $0.000^{*}$ & $0.039^{*}$ & 0.123 & 0.245 & 1.000 & 0.286 & 0.242 & 0.494 \\
Lai et al" $^{\prime \prime}$ & $0.008^{*}$ & $0.00 I^{*}$ & 0.738 & 0.9 & 0.697 & 0.293 & 0.111 & 0.775 \\
Meta-analysis & 0.249 & $0.045^{*}$ & 0.241 & $0.033^{*}$ & 0.869 & 0.210 & 0.717 & 0.605 \\
\hline
\end{tabular}

Note: $* P<0.005$.

Abbreviations: RAPD, robot-assisted pancreaticoduodenectomy; PD, pancreaticoduodenectomy; LOS, length of hospital stay; POPF, postoperative pancreatic fistula; R0, margin-negative resection. 
In case-matched studies, the mean operative time ranged from 444.0 to 491.5 minutes with an estimated mean intraoperative blood loss ranging from $247.0 \mathrm{~mL}$ to $485.0 \mathrm{~mL}$ (Table 3).

Table 4 summarizes some of the technical details of RAPD.

Pancreatic remnants were managed according to different techniques. Most pancreata $(113 / 317 ; 35.7 \%)$ were drained either into the jejunum $(97 / 113 ; 85.8 \%)$ or into the stomach $(16 / 113 ; 5.0 \%)$. Duct occlusion $(48 / 317 ; 15.1 \%)$ was also employed by Giulianotti and Zhan. ${ }^{7,8}$ Information on the use of a duct stent was missing in most series.

\section{Effectiveness}

Table 5 summarizes pathological parameters. Most patients $(224 / 317 ; 70.6 \%)$ were operated on because of malignant tumors, though only a minority were diagnosed with ductal adenocarcinoma of the pancreas $(122 / 317 ; 38.5 \%)$. The mean number of examined lymph nodes and the rate of positive surgical margins indicated that RAPD could be an appropriate operation for selected patients diagnosed with periampullary and pancreatic tumors.

Unfortunately, the issue of costs was addressed only in two manuscripts. Both reported additional costs, as compared to open surgery. Boggi et al estimated the additional costs to be 6,193 Euro per patient. ${ }^{9}$ Similarly, Chalikonda et al estimated the additional costs of RAPD at 4,000-5,000 US dollars. ${ }^{5}$

To further elucidate the effectiveness of RAPD, we conducted a meta-analysis on the three case-matched studies that are currently available. ${ }^{5,10,11}$ Overall, there were 136 open PDs and 94 RAPDs. The following parameters were evaluated: operative time, length of hospital stay, rate of margin-free (R0) resection, number of examined lymph nodes, prevalence of malignant tumors, postoperative morbidity, incidence of POPF, and postoperative mortality.

RAPD appeared to be associated with a shorter length of hospital stay (Figure 2) and a higher lymph node yield (Figure 3) (Table 6).

\section{Potential selection biases}

None of the studies available was prospective and randomized. Because of the retrospective nature of examined studies, and hence the lack of prospective selection criteria, patients were operated on because of a variety of pancreatic and periampullary diseases, including both benign and malignant tumors. Crucial information, such as tumor stage, is missing. Pancreatic and periampullary tumors are indeed staged differently based on tumor type.
Case-matched studies also showed differences between comparison groups. In the study from Buchs et al, ${ }^{10}$ the two study groups were mismatched for age $(P=0.04)$, body mass index $(P=0.01)$, and ASA class $(P=0.01)$. Further, patients with different tumor types were treated, and the technique used for pancreatic anastomosis was also different between study groups $(P=0.0001)$. In the studies by Chalikonda et $\mathrm{al}^{5}$ and Lai et al, ${ }^{11}$ different types of tumors were treated in the study groups.

\section{Incomplete outcome data}

Again, because of the retrospective design of available studies, considerable information was missing or incomplete. Cost analysis, for instance, was available in only two studies.

\section{Conclusion and future perspectives}

The intrinsic technical difficulties of open PD have put generations of surgeons to the test, and the challenge continues nowadays. As a consequence, laparoscopic PD has remained one the last fortress of open surgery though a few gifted surgeons have safely implemented this operation in a large series of patients, ${ }^{12-15}$ even when dealing with the resection and reconstruction of the superior mesenteric/portal vein. ${ }^{16}$ The intrinsic limitations of laparoscopy, however, make these achievements difficult to duplicate on a large scale.

The dVss is not a robot in the narrower sense of the term, since it is not capable of any autonomous or programmed action. It is rather a telepresence manipulator able to duplicate the movements of surgeon's hands at the tip of miniaturized wristed instruments, having seven degrees of freedom like the human wrist. Further, the dVss provides immersive magnified $(10 \times-15 \times) 3 \mathrm{D}$ high-definition view, fully restoring hand-eye coordination, tremor filtration, and scaled motion. ${ }^{17}$ These tremendous technology improvements are particularly rewarding, in comparison with standard laparoscopy, especially when delicate dissections or multiple incorporeal sutures are needed. Thus, the dVss would seem the ideal tool to make laparoscopic PD safely achievable by a larger population of pancreatic surgeons.

In this review, we have decided to consider only the articles reporting on ten or more patients to limit effect of the learning curve on reported outcomes. ${ }^{18}$ Actually, sufficient information is not available on the number of procedures that should be carried out to complete the learning curve for RAPD. It is instead likely that most surgeons practicing RAPD are still on their learning curve or have just completed it. This could be a bias when comparing the results of RAPD 
with those of open PD. Further, it is likely that in their initial experience, most authors have preferred to avoid the most challenging operative scenarios. Typically, patients having easily resectable diseases have soft pancreatic remnants with small ducts. It is known that these circumstances increase the rate and severity of POPF, ${ }^{19}$ making meaningful comparison with open PD unfeasible.

Perhaps because RAPD is still in its infancy, all authors described different techniques. Even authors describing fully robotic RAPD used different techniques. This is not surprising, considering that the technique for open PD has not been standardized yet. Some of these differences, however, could be solved by the availability of the newer robotic generation, the $\mathrm{dVss} \mathrm{Xi}$. While the core technology and the basic working principles of the newer robotic system are unchanged, there are several innovations that could facilitate either the standardization of the surgical technique or a wider adoption of RAPD. The new system, indeed, permits camera hopping among ports, improves patient accessibility by the anesthesia team, increases internal work volume despite reducing the risk of inter-arm and patient collision while allowing for closer port positioning, and is expected to allow coordinated movements of the robotic arms with a specifically designed bed.

From a technical point of view, one of the surgical aspects that is not expected to change, even with the newer robotic system, is the method used to divide the pancreas neck, which is thought to be key in the development of POPF. In open surgery, a sharp division of the pancreatic neck is advised to preserve blood supply to the resection margin. Bleeding is partially prevented by placing stay sutures at the superior and inferior borders of the pancreatic neck, and arrested by individually suturing spurting bleeders while noting the position of the main pancreatic duct. ${ }^{20}$ In RAPD, the division of the pancreatic neck employs different types of energy devices as sharp division is unpractical and a dry cut surface is preferable. All available energy devices are associated with lateral thermal spread, which induces collateral tissue injury. ${ }^{21-23}$

When considering feasibility, RAPD appears to be feasible in most selected patients. Selection is indeed key, and there is no evidence that RAPD can be safely performed in an unselected population of patients. RAPD requires longer operative times when compared to open surgery. Reported incidence of conversion to open surgery ranged from $3.0 \%$ to $10.0 \%$. Excluding patients who were not able to tolerate pneumoperitoneum, in most of the other patients, conversion to open surgery was caused by tumor adherence to the superior mesenteric/portal vein, difficulties in achieving complete oncologic clearance, and challenging dissection. Most of these instances are potentially predictable. It is worth noting that timely conversion to open surgery should not be viewed as treatment failure, but should be rather considered prudent surgical practice. The entire team, including the operating room personnel, should be ready to face this occurrence, especially in case of bleeding. One intraoperative death, caused by portal vein injury, was reported despite conversion to open surgery. ${ }^{5}$

While little doubt exists that robotic assistance increases operating costs, ${ }^{24}$ none of the available studies was specifically designed to provide full economic evaluation of RAPD. The study by Chalikonda et $\mathrm{al}^{5}$ actually provided only a generic estimation of operating costs without describing the methodology or reporting detailed results. The study by Boggi et al estimated the operating costs of RAPD, exceeding those of open PD, considering operative and anesthesia time, robotic equipment, laparoscopic disposable devices, and the cost of the robotic system as amortized by case, including maintenance. ${ }^{9}$ However, even this study did not provide full economic evaluation of RAPD, which includes four types of analyses: cost-minimization analysis, cost-effectiveness analysis, cost-benefit analysis, and cost-utility analysis. ${ }^{24}$

However, whether the additional costs of robotic assistance are worth being covered cannot be answered only by economic analysis. Robotic assistance is expected to facilitate performance of some advanced operations that, like RAPD, are carried out in deep spaces and require both fine dissections and complex intracorporeal suturing. Should these advantages be confirmed, and proved to be associated with improved task quality and patient outcome, the initial investment in the robotic technology would be justified, thus significantly reducing the costs of robotic assistance.

Current results show that RAPD is safely feasible, with morbidity and mortality rates in the range reported for open PD. Perhaps when the learning curve is completed and when the results on patients with hard pancreatic remnants and dilated ducts are available, a clear advantage in comparison with open PD may become evident. At present, RAPD is safe enough to be implemented in specialized centers with sound laparoscopic background.

Based on this review, we believe that RAPD is here to stay, although nearly everything remains to be standardized and demonstrated. As robotic technology continues to improve, current limitations of RAPD are expected to become the next challenges. Eventually, RAPD will be available to a larger proportion of patients at specialized centers. We discourage surgeons not dedicated to pancreatic surgery, not 
having a sound background on advanced laparoscopic techniques, and not having received a formal training in robotic surgery to pursue RAPD in the occasional patient.

\section{Disclosure}

The authors declare no conflict of interest in this work.

\section{References}

1. Gagner M, Pomp A. Laparoscopic pylorus-preserving pancreatoduodenectomy. Surg Endosc. 1994;8(5):408-410.

2. Boggi U, Amorese G, Vistoli F, et al. Laparoscopic pancreaticoduodenectomy: a systematic literature review. Surg Endosc. 2015; 29(1):9-23.

3. Hockstein NG, Gourin CG, Faust RA, Terris DJ. A history of robots: from science fiction to surgical robots. J Robot Surg. 2007;1(2):113-118.

4. Hanly E, Talamini M. Robotic abdominal surgery. Am J Surg. 2004; 188(4A):S19-S26.

5. Chalikonda S, Aguilar-Saavedra JR, Walsh RM. Laparoscopic roboticassisted pancreaticoduodenectomy: a case-matched comparison with open resection. Surg Endosc. 2012;26(9):2397-2402.

6. Zureikat AH, Moser AJ, Boone BA, Bartlett DL, Zenati M, Zeh HJ 3rd. 250 Robotic pancreatic resections. Ann Surg. 2013;258(4):554-562.

7. Zhan Q, Deng XX, Han B, et al. Robotic-assisted pancreatic resection: a report of 47 cases. Int J Med Robot. 2013;9(1):44-51.

8. Giulianotti PC, Sbrana F, Bianco FM, et al. Robot-assisted laparoscopic pancreatic surgery: single-surgeon experience. Surg Endosc. 2010;24(7):1646-1657.

9. Boggi U, Signori S, De Lio N, et al. Feasibility of robotic pancreaticoduodenectomy. Br J Surg. 2013;100(7):917-925.

10. Buchs NC, Addeo P, Bianco FM, Ayloo S, Benedetti E, Giulianotti PC. Robotic versus open pancreaticoduodenectomy: a comparative study at a single institution. World J Surg. 2011;35(12):2739-2746.

11. Lai EC, Yang GP, Tang CN. Robot-assisted laparoscopic pancreaticoduodenectomy versus open pancreaticoduodenectomy - a comparative study. Int J Surg. 2012;10(9):475-479.

12. Croome KP, Farnell MB, Que FG, et al. Total laparoscopic pancreaticoduodenectomy for pancreatic ductal adenocarcinoma: oncologic advantages over open approaches? Ann Surg. 2014;260(4):633-638.
13. Asbun HJ, Stauffer JA. Laparoscopic vs open pancreaticoduodenectomy: overall outcomes and severity of complications using the accordion severity grading system. J Am Coll Surg. 2012;215(6):810-819.

14. Palanivelu C, Rajan PS, Rangarajan M, et al. Evolution in techniques of laparoscopic pancreaticoduodenectomy: a decade long experience from a tertiary center. J Hepatobiliary Pancreat Surg. 2009;16(6): 731-740.

15. Kim SC, Song KB, Jung YS, et al. Short-term clinical outcomes for 100 consecutive cases of laparoscopic pylorus-preserving pancreatoduodenectomy: improvement with surgical experience. Surg Endosc. 2013;27(1):95-103.

16. Croome KP, Farnell MB, Que FG, et al. Pancreaticoduodenectomy with major vascular resection: a comparison of laparoscopic versus open approaches. J Gastrointest Surg. 2014;19(1):189-194.

17. Boggi U, Vistoli F, Signori S, et al. Robotic renal transplantation: first European case. Transpl Int. 2011;24(2):213-218.

18. Birkmeyer JD, Siewers AE, Finlayson EV, et al. Hospital volume and surgical mortality in the United States. N Engl J Med. 2002;346(15): $1128-1137$.

19. Ansorge C, Strommer L, Andren-Sandberg A, Lundell L, Herrington MK, Segersvard R. Structured intraoperative assessment of pancreatic gland characteristics in predicting complications after pancreaticoduodenectomy. Br J Surg. 2012;99(8):1076-1082.

20. Strasberg SM, Drebin JA, Mokadam NA, et al. Prospective trial of a blood supply based technique of pancreaticojejunostomy: effect on anastomotic failure in the Whipple procedure. J Am Coll Surg. 2002; 194(6):746-758.

21. Lämsä T, Jin HT, Nordback PH, Sand J, Luukkaala T, Nordback I. Pancreatic injury response is different depending on the method of resecting the parenchyma. $J$ Surg Res. 2009;154(2):203-211.

22. Emam TA, Cuschieri A. How safe is high-power ultrasonic dissection? Ann Surg. 2003;237(2):186-191.

23. Družijanić N, Pogorelić Z, Perko Z, Mrklić I, Tomić S. Comparison of lateral thermal damage of the human peritoneum using monopolar diathermy, harmonic scalpel and LigaSure. Can J Surg. 2012;55(5): 317-321.

24. Turchetti G, Palla I, Pierotti F, Cuschieri A. Economic evaluation of da Vinci-assisted robotic surgery: a systematic review. Surg Endosc. 2012;26(3):598-606.
Robotic Surgery: Research and Reviews

\section{Publish your work in this journal}

Robotic Surgery: Research and Reviews is an international, peer reviewed, open access, online journal publishing original research, commentaries, reports, and reviews on the theory, use and application of robotics in surgical interventions. Articles on the use of supervisory-controlled robotic systems, telesurgical devices, and shared-control systems are

\section{Dovepress}

invited. The manuscript management system is completely online and includes a very quick and fair peer review system, which is all easy to use. Visit http://www.dovepress.com/testimonials.php to read real quotes from published authors. 